\title{
Resolução de conflitos em centros integrados de cidadania: uma abordagem à luz da perspectiva sociotécnica de grupos de trabalho
}

\author{
Almir Cordeiro Júnior* \\ Mônica de Fátima Bianco**
}

\begin{abstract}
Resumo
Por meio da análise do modelo de Centro Integrado de Cidadania, implantado em Vitória, e dos equipamentos que 0 antecederam, busca-se, neste artigo: identificar os serviços que devem estar presentes num equipamento urbano dessa natureza, à luz dos instrumentos governamentais que originaram sua concepção; categorizar os serviços identificados segundo algumas das principais classificações existentes na literatura específica (Chase, 1978; Lovelock, 1983; Schmenner, 1986); discutir as unidades de atendimento como integrantes de um processo de produção induzido pelo cliente, à luz das estruturas básicas propostas por Wild (1977); direcionar o foco da abordagem para as unidades que estão voltadas à resolução pacífica de conflitos, confrontando seus subsistemas técnico e social com os pressupostos da Escola Sociotécnica (Biazzi Júnior, 1994); comparar a atuação dessas unidades com 0 job design para grupos semiautônomos (Cherns, 1994) e, por fim, comentar a importância da estruturação dessas unidades como grupos autogeridos, mostrando que esta abordagem contribui sobremaneira para a integração operacional e a gestão dessas unidades.
\end{abstract}

Palavras-chave: Taxonomia de Serviço; Resolução Pacífica de Conflitos; Grupos Autogeridos.

\begin{abstract}
Through the analysis of a model Integrated Center of Citizenship, established in Vitória, and of the organizations that preceded, we try, in this article: to identify the services which must be present in an urban organization of this nature, having in mind the governamental instruments that originated its conception: to categorize the services identified according to some of the principal classifications present in specific literature (Chase, 1978; Lovelock, 1983; Schemenner, 1986); to discuss the units of service as part of a process of production induced by the client, in the light of the basic strutures proposed by Wild (1977); to direct the focus of the approach to the units that are concerned with the pacific solutions of conflicts, confronting its technical and social subsystems with the pressupositions of the Sociotechnical School (Biazzi Jr, 1994); to compare the actuations of these units with the job design for semi-autonomous (Cherns, 1994) and, finally, to comment on the importance of the structuring of these units as self-sufficient managed groups, showing that this approach contributes, to a great extent, to the operational integration and management of these units.
\end{abstract}

Keywords: Taxonomy of Services ; Pacific Solution of Services ; Self-Sufficient Managed Groups.

\section{Introdução}

Num cenário organizacional com mais de 15 órgãos nas esferas federal, estadual e municipal, convivendo com empresas da iniciativa privada e buscando oferecer serviços aos cidadãos, é fundamental uma metodologia de estruturação que integre todos esses serviços, com agilidade no atendimento, qualidade no serviço e resolubilidade nas soluções implementadas.

\footnotetext{
* Professor da Universidade Novo Milênio - Campus Serra, ES. Mestre em Administração pela UFES. E-mail: almircjr@ hotmail.com

** Professora do Programa de Pós-Graduação em Administração da Universidade Federal do Espírito Santo - UFES. E-mail: mfbianco@ npd.ufes.br Artigo recebido em outubro de 2004 e aceito em janeiro de 2005.
} 
Este artigo pretende mostrar a importância da estruturação das unidades componentes de centros integrados de cidadania - ou de organizações com concepções semelhantes -, como grupos autogeridos, evidenciando que essa abordagem contribui para a integração operacional e a gestão dessas unidades.

Inicialmente, o texto apresenta o Centro Integrado de Cidadania implantado em Vitória (CIC-Vitória) e os serviços de que este dispõem, conforme os instrumentos governamentais que originaram sua concepção. Em seguida, os serviços identificados são categorizados de acordo com algumas das principais classificações da literatura específica (CHASE, 1978; LOVELOCK, 1983; SCHMENNER, 1986). Num terceiro momento, a partir dessa categorização, são discutidas as unidades de atendimento como integrantes de um processo de produção induzido pelo cliente, à luz das estruturas básicas propostas por Wild (1977). O foco da abordagem é, então, direcionado para as unidades voltadas para a resolução pacífica de conflitos, confrontando seus subsistemas técnico e social com os pressupostos da escola sociotécnica (BIAZZI JR, 1994). Finalmente, é comparada a atuação dessas unidades com o job design para grupos semi-autônomos (CHERNS, 1994), quando será mostrado que, em maior ou menor grau, elas se identificam com os princípios ali estabelecidos.

A fonte empírica deste texto foi uma pesquisa que envolveu não apenas os pesquisadores, mas também pessoas atuantes nas unidades prestadoras de serviço no CIC-Vitória. A investigação teve caráter qualitativo e intervencionista e foi feita através de entrevistas com gerentes, profissionais especializados e atendentes. Nessas entrevistas, procurou-se identificar os processos de serviço nos órgãos de origem e adaptá-los à realidade do Centro Integrado de Cidadania em questão.

\section{A origem dos centros integrados de cidadania}

A origem dos centros integrados de cidadania remonta a setembro de 1991, com o surgimento da primeira unidade de atendimento integrado, em Santa Catarina (ANGELIM, 2003). A experiência foi difundida no âmbito do Programa de Qualidade no Serviço Público, com o apoio dado à instalação de uma rede nacional de unidades de atendimento integrado (BRASIL, 2002c, p. 97). A iniciativa seguia a diretriz que determinava a substituição do paradigma do processo pelo paradigma da qualidade no atendimento ao cidadão, procurando centralizar num único local a emissão da documentação civil básica.

Anos depois, no âmbito do Programa Nacional dos Direito Humanos (BRASIL, 1996, p.23-24; 2002a, p.21; 2002b, p.17), facilitar o acesso do cidadão à Justiça é definido como foco dos centros integrados de cidadania, tendo como paradigma a resolubilidade como condição indispensável e fundamental para a garantia dos direitos civis.

Por último, mas não menos importante, apresenta-se o Plano Nacional de Segurança Pública (BRASIL, 2000, p. 39) preconizando a presença nos centros integrados de cidadania de órgãos voltados para a resolução pacífica de conflitos, seguindo o paradigma da interação entre os atores sociais envolvidos, de acordo com a visão de que o combate ao crime, em suas diversas manifestações, só seria efetivo se contemplasse, além de ações repressivas, outras tantas de cunho social e preventivo da violência. 


\section{Quadro 1}

\begin{tabular}{|c|c|c|}
\hline \multicolumn{3}{|c|}{ idades de atendimento participantes do CIC-Vitória } \\
\hline $\begin{array}{l}\text { MODELO DE } \\
\text { ORIGEM }\end{array}$ & UNIDADES DE ATENDIMENTO & ÁREA DE ATUAÇÃO \\
\hline \multirow{15}{*}{$\begin{array}{l}\text { Programa de } \\
\text { Qualidade no Serviço } \\
\text { Público }\end{array}$} & Cartório de registro civil & \multirow{4}{*}{$\begin{array}{l}\text { Acesso à documentação } \\
\text { civil básica }\end{array}$} \\
\hline & Empresa Brasileira de Correios e Telégrafos & \\
\hline & Cartório eleitoral & \\
\hline & Delegacia Regional do Trabalho & \\
\hline & Departamento Estadual de Trânsito - Detran & \multirow{7}{*}{$\begin{array}{l}\text { Apoio operacional ao } \\
\text { acesso à documentação } \\
\text { civil básica }\end{array}$} \\
\hline & Polícia Civil & \\
\hline & Polícia Federal & \\
\hline & Banco do Estado do Espírito Santo S.A. & \\
\hline & Banco do Brasil S.A. & \\
\hline & Caixa Econômica Federal & \\
\hline & Copiadora & \\
\hline & Fotógrafo & \multirow{2}{*}{$\begin{array}{l}\text { Acesso a serviços não- } \\
\text { presenciais }\end{array}$} \\
\hline & Internet pública & \\
\hline & Juizado Especial Cível & Acesso à Justiça \\
\hline & Juizado Especial Criminal & \multirow{10}{*}{$\begin{array}{l}\text { Apoio operacional ao } \\
\text { acesso à Justiça } \\
\text { Acesso às ações sociais } \\
\text { preventivas da violência }\end{array}$} \\
\hline \multirow{6}{*}{$\begin{array}{l}\text { Programa Nacional } \\
\text { de Direitos Humanos }\end{array}$} & Delegacias especializadas & \\
\hline & Juizado Especial Federal & \\
\hline & Ministério Público & \\
\hline & Defensoria Pública & \\
\hline & Atendimento aos advogados & \\
\hline & Assistência jurídica gratuita & \\
\hline \multirow{4}{*}{$\begin{array}{l}\text { Plano Nacional de } \\
\text { Segurança Pública }\end{array}$} & Atendimento intrafamiliar & \\
\hline & SOS Impunidade & \\
\hline & Procon municipal & \\
\hline & Universidade Federal do Espírito Santo & $\begin{array}{l}\text { Capacitação de lideranças } \\
\text { comunitárias }\end{array}$ \\
\hline
\end{tabular}

Fonte: Memorial Descritivo do CIC-Vitória

Assim, nascem os Centros Integrados de Cidadania, como estruturas implantadas nas cidades, destinadas à prestação de serviços públicos de caráter social, estruturados a partir de parcerias entre o Poder Executivo (federal, estadual e municipal), o Poder Judiciário e entidades da sociedade civil, buscando:

a) prestar serviços públicos presenciais integrados, onde as relações com o cidadão priorizem a qualidade no atendimento;

b) garantir o respeito aos direitos humanos, promovendo o acesso da população à Justiça, principalmente, da parcela hipossuficiente e despossuída de conhecimento sobre seus direitos básicos inerentes à cidadania, e

c) reduzir a violência urbana, buscando solucionar conflitos, através da interação e da conciliação entre os atores sociais envolvidos.

Dessa identidade multifacetada, sobressaem os paradigmas da qualidade, da resolubilidade e da interação como fundamentos sobre os quais começou a ser planejado o modelo organizacional do Centro Integrado de Cidadania de Vitória, experiência ímpar nesses moldes, integrando 25 unidades de atendimento voltadas para a prestação de serviços públicos presenciais. 


\section{Classificação dos serviços do Centro Integrado de Cidadania de Vitória}

A classificação ocupa um papel central na compreensão sistemática e na previsão de vários fenômenos. Não é diferente com os serviços. O que se pretende, ao classificá-los, é segmentar os serviços analisados em grupos de características semelhantes e, a partir daí, refletir sobre que práticas de organização e operacionalização são mais aplicáveis a um ou a outro grupo.

Embora vários modelos de classificação tenham sido elaborados para a área de serviços, nenhum conseguiu se impor de tal forma que conseguisse consenso entre os pesquisadores. Assim, dependendo do objeto da abordagem e das preferências pessoais do pesquisador, as variáveis de classificação utilizadas são distintas.

Para o caso específico dos serviços prestados no Centro Integrado de Cidadania de Vitória foram selecionadas e adaptadas algumas das variáveis propostas por Chase (1978), Lovelock (1983) e Schemenner (1986), bem como, dentre os serviços ofertados, aqueles vinculados ao acesso à documentação civil básica, à Justiça e às ações sociais preventivas da violência, por serem mais representativos de cada um dos modelos que originaram o CIC-Vitória.

Para mostrar o posicionamento de cada serviço quanto às variáveis escolhidas, foram usadas matrizes onde as variáveis se distribuem nos eixos horizontal e vertical e os serviços se aglutinam nos quadrantes, de acordo com as semelhanças que guardam entre si e com as variáveis.

\section{Extensão do contato com o cliente quando da prestação do serviço x prazo de execução do atendimento (Adaptado de CHASE, 1978, p.137-142)}

A extensão do contato (ou intensidade do contato) é verificada pelo tempo da presença física do cliente no sistema de prestação de serviços. Essa extensão pode ser medida pelo percentual de tempo que o cliente permanece no sistema em relação ao tempo total do sistema. Por outro lado, permanecer no sistema implica participação direta do cliente no processo.

Em serviços que envolvam alta intensidade de contato, o cliente determina o momento da demanda, define a natureza do serviço - pela participação direta no processo e pela interação constante com o prestador do serviço - e percebe a qualidade do serviço a partir do atendimento recebido.

Já em serviços que envolvam baixa intensidade de contato, o cliente não exerce nenhuma influência direta no processo produtivo - pois muitas vezes nem está presente quando tal processo é efetivado-; ou seja, ele dispara o processo, se ausenta e retorna para receber o serviço executado. Nesse caso, sua visão de qualidade está vinculada mais a uma percepção personalizada do serviço que, na verdade, não existe, uma vez que ele se orienta pela economia de escala do processamento em massa. Para cruzar essa variável com as principais considerações propostas por Chase, visando ao desenho dos sistemas de alto e baixo contato, selecionamos o tempo-padrão (ou prazo de execução).

O tempo-padrão se traduz pela possibilidade ou não de definir o número de contatos efetuados no processo de prestação de serviços. Essa quantidade pode variar de uns poucos até um continuum de atendimentos. Em serviços que apresentem rígido prazo de execução, o atendimento ao cliente é realizado através de um contato (o cliente solicita, aguarda o processamento e recebe o serviço) ou, no máximo, de dois, quando o cliente solicita e retorna para receber o serviço executado.

Já nos serviços que apresentam prazo de execução flexível, o solicitado pelo cliente só é passível de ser atendido através de uma série de contatos onde, participativa e gradualmente, o resultado final satisfatório vai sendo alcançado.

No quadro 2, o eixo horizontal contempla os contatos de baixa e de alta intensidade e o eixo vertical, os prazos rígido e flexível de execução. 


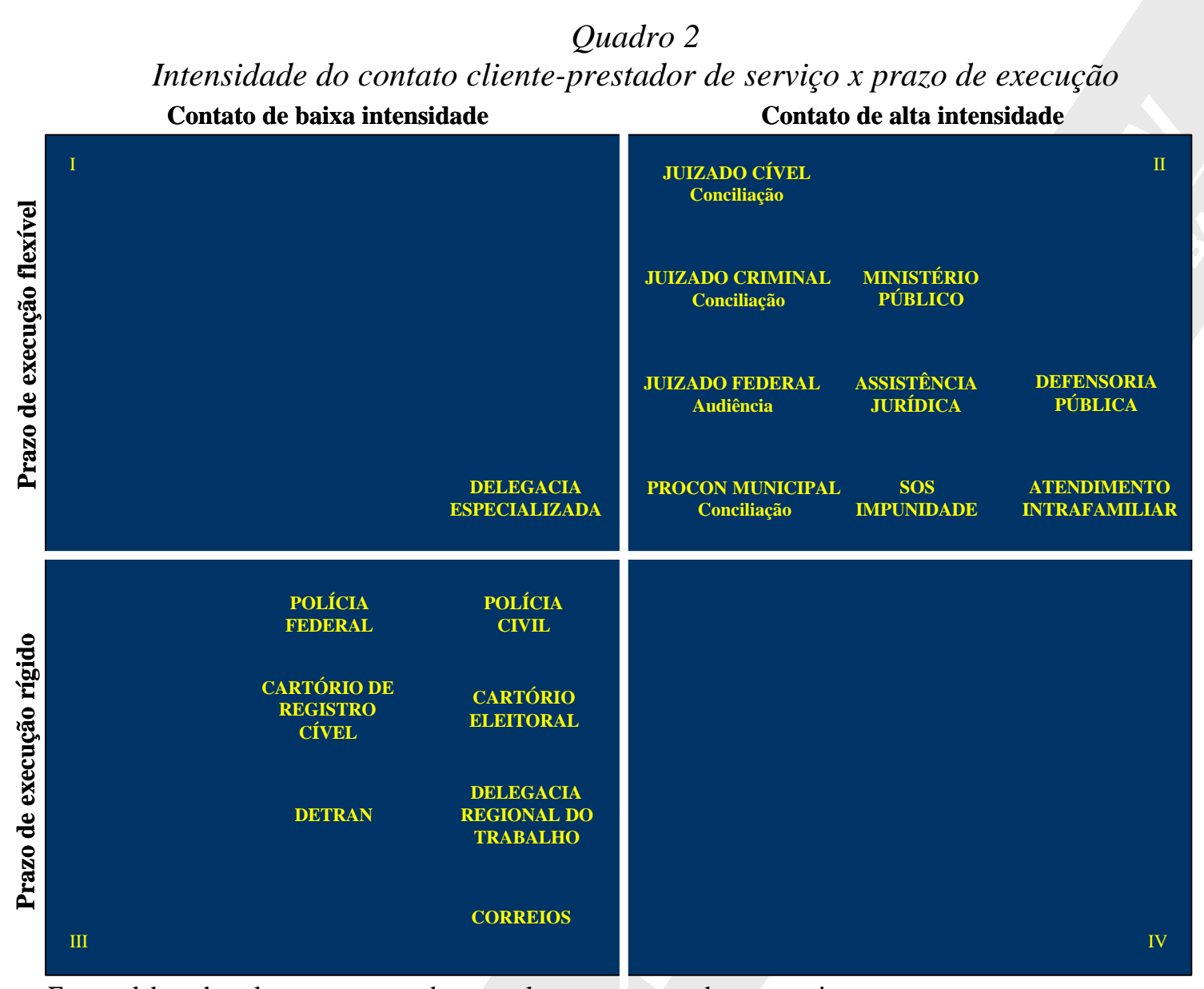

Fonte: elaborado pelos autores, com base nos levantamentos sobre os serviços.

Os serviços realizados pela delegacia especializada em infrações penais de menor potencial ofensivo ficaram no primeiro quadrante: "contato de baixa intensidade e prazo de execução flexível". Neles, o cidadão está presente num primeiro momento, o da abertura do processo; depois, aguarda o encaminhamento de sua questão, pouco influindo no desenrolar dos acontecimentos que seguem um rito preestabelecido. Quanto ao prazo de execução, este não tem como ser previsto, variando de caso para caso.

Os serviços de atendimento especializado no âmbito do acesso à Justiça e às ações sociais preventivas da violência ficaram agrupados no segundo quadrante: "contato de alta intensidade e prazo de execução flexível", isto é, o cidadão está presente num continuum de atendimentos que compõe o seu processo ou prontuário, participa intensamente desde o início até à conclusão do processo produtivo - interagindo com o prestador dos serviços -, e o prazo de execução do atendimento não tem como ser previsto, variando não só de caso para caso, como também quanto à duração de cada atendimento.

Já os serviços relacionados com o acesso à documentação civil básica agruparam-se no terceiro quadrante: "contato de baixa intensidade e prazo de execução rígido"; isto é, o cidadão está presente por um curto espaço de tempo - normalmente um único atendimento ou, no máximo, dois sequienciais e imediatos - nos casos de concessão de habilitação (Detran) e de identidade (Polícia Civil) -, não exerce influência direta no processo produtivo - predefinido pelo prestador dos serviços -, e o prazo de execução obedece à duração prevista para cada caso. 


\section{Destinatário da prestação do serviço $x$ natureza da prestação do serviço (Adaptado de LOVELOCK, 1983, p.9-20)}

O destinatário da prestação do serviço diz respeito sobre o que (bens) ou sobre quem (pessoas) é exercida a prestação do serviço. A natureza da prestação do serviço se traduz no grau de tangibilidade ou intangibilidade dos atos do serviço.

No quadro3, o eixo horizontal contempla o destinatário da prestação do serviço; o eixo vertical, a natureza dos atos do serviço.

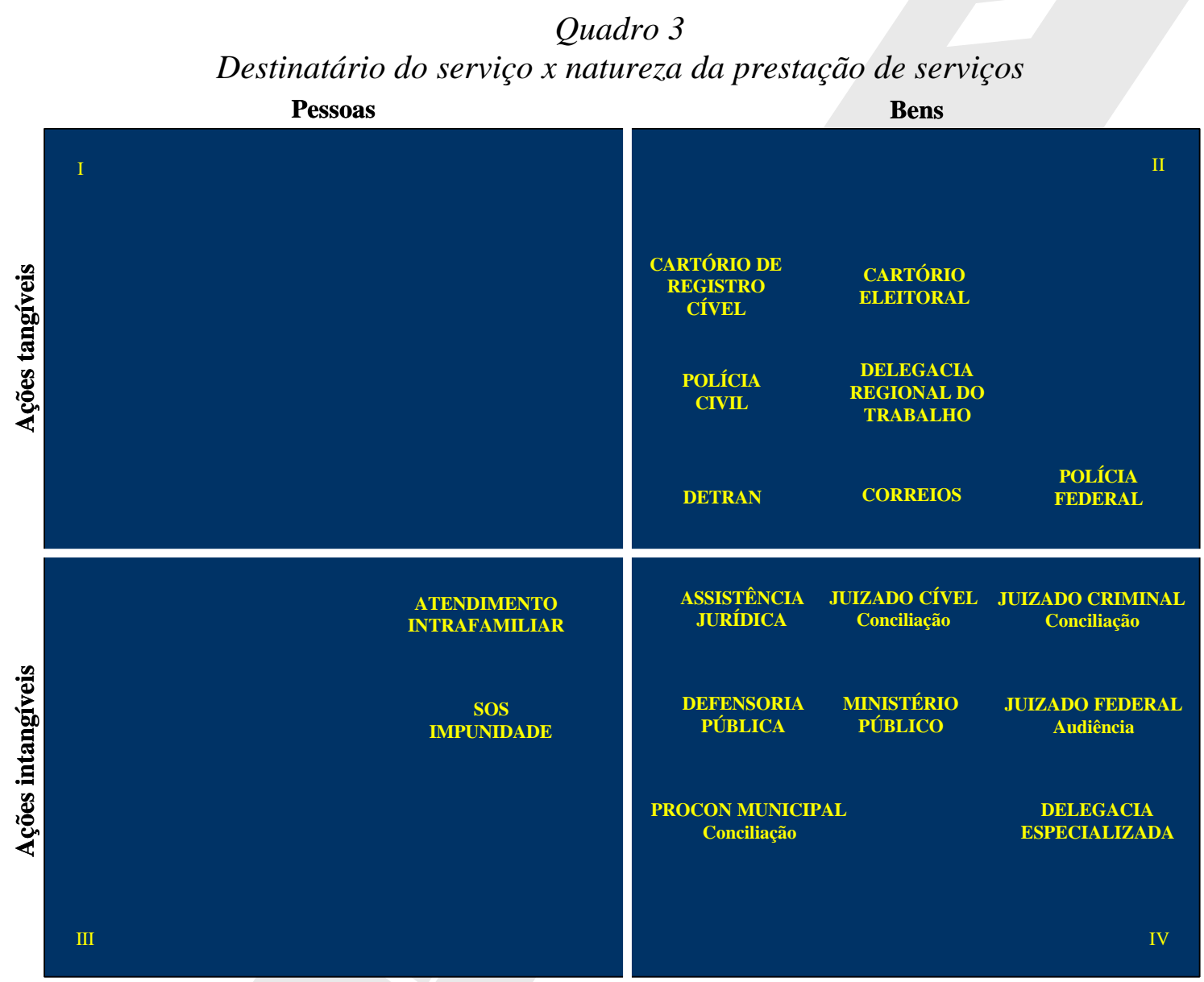

Fonte: elaborado pelos autores, com base nos levantamentos sobre os serviços.

No segundo quadrante, "ações tangíveis atuantes sobre bens", estão os serviços voltados aos bens dos clientes e outras "posses físicas". Muitas dessas atividades guardam relação com as operações fabris, onde nem sempre a produção e o consumo ocorrem ao mesmo tempo. É menor a exigência da presença física do cliente no processo, limitando-se esta, muitas vezes, ao início e ao término do mesmo. No terceiro quadrante, "ações intangíveis atuantes sobre pessoas" situam-se os serviços dirigidos "à mente" do cliente. Esses serviços moldam atitudes e influenciam comportamentos. Normalmente, os clientes que demandam tais serviços estão em situação de fragilidade, de dependência e são passíveis de manipulação, o que demanda dos profissionais envolvidos no atendimento, conhecimentos específicos e padrões éticos consolidados. A presença do cliente e sua interação com o prestador dos serviços é fundamental durante todo o processo. No quarto quadrante, "ações intangíveis atuantes sobre bens", estão os serviços dirigidos a realidades do cliente, apreendidas pela percepção e/ou pela interlocução. Esses serviços são altamente dependentes da captação e do processamento de informações, envolvendo profissionais especializados. Já o envolvimento do cliente é determinado pela necessidade de interação com o prestador de serviços e pelo fato dele deter as informações necessárias ao satisfatório atendimento. 
O acesso à documentação civil básica ficou no segundo quadrante, pois a prestação do serviço ocorre no ato da confecção (ou renovação) de um documento, do qual o cidadão passa a ter a posse física. Por sua vez, o cidadão está presente por um curto espaço de tempo, interagindo no processo em seu início (para solicitação e pagamento de taxas) e no seu término (para receber o documento).

Todos os serviços de atendimento psicossocial - prestados por psicólogos, sociólogos, assistentes sociais e profissionais da área médica, quando o atendimento assim o exigir - voltados para as vítimas da violência familiar e aos parentes de vítimas de homicídio, com o propósito de promover a reinserção social do cliente demandante dos serviços, ficaram posicionados no segundo quadrante.

Os serviços de atendimento especializado no âmbito do acesso à Justiça e parte dos serviços relacionados às ações sociais preventivas da violência (Procon municipal, assistência jurídica gratuita e Ministério Público) ficaram agrupados no quarto quadrante; isto é, o produto da prestação do serviço incide sobre um inquérito policial, sobre um processo em tramitação na Justiça ou num processo de resolução de conflito na esfera das relações de consumo, com o cliente interagindo no decorrer de toda a prestação do serviço.

\section{Intensidade do papel do pessoal de atendimento x extensão em que as características do serviço são personalizadas (Adaptado de LOVELOCK, 1983, p.9-20)}

A intensidade do papel do pessoal de atendimento diz respeito ao poder do prestador do serviço em modificá-lo e em tomar as decisões que melhor atendam às necessidades individuais do cliente. A prestação de serviços pode ser adaptada às necessidades do cliente (personalizada) ou sempre com as mesmas características (padronizada).

No quadro 4, o eixo horizontal contempla a personalização ou a padronização dos serviços e o eixo vertical, ao alto ou ao baixo poder do prestador do serviço em tomar decisões. Todos os serviços de atendimento especializado no âmbito do acesso à Justiça e das ações sociais preventivas da violência ficaram agrupados no primeiro quadrante - mobilidade do prestador do serviço quanto à tomada de decisões e geração de um serviço personalizado; - isto é, o prestador do serviço possui ampla autonomia para modificá-lo, seja optando por abordagens diferenciadas, quanto envolvendo outros profissionais especializados no atendimento ou redirecionando o fluxo de sua execução, o que resulta numa prestação de serviço personalizada, em que cada produto obtido guarda características próprias e se diferencia dos demais. 


\section{Quadro 4}

Poder de decisão do prestador de serviços x extensão da personalização dos serviços
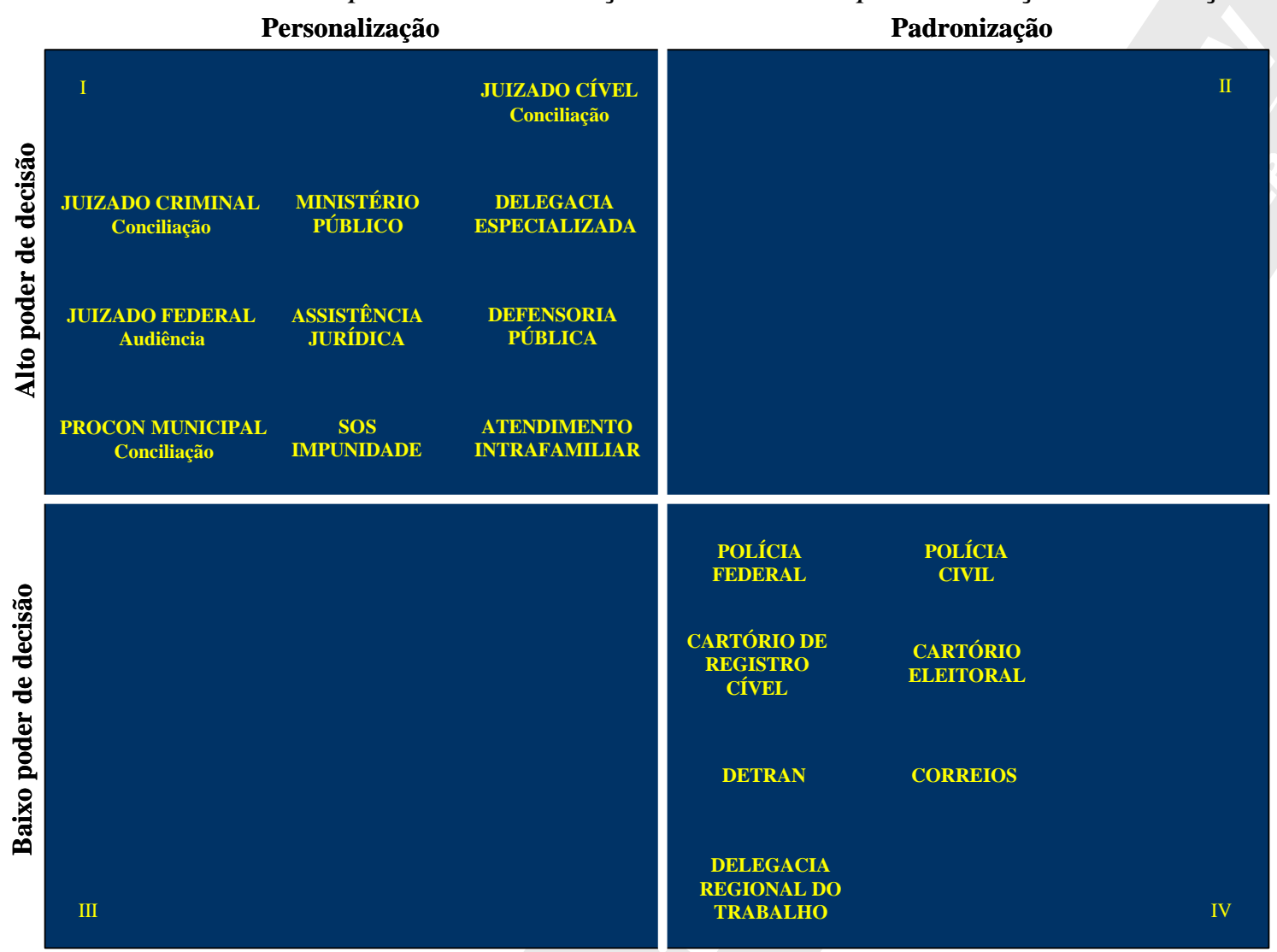

Fonte: elaborado pelos autores, com base nos levantamentos sobre os serviços.

No quarto quadrante, posicionaram-se os serviços relacionados com o acesso à documentação civil básica nenhuma autonomia do prestador do serviço para modificá-lo e geração de serviço padronizado - ;isto é, o prestador do serviço não pode alterá-lo, quer em sua forma, quer em sua essência, pois o mesmo se dá através de procedimentos predefinidos, resultando sempre em produtos idênticos.

\section{Grau de intensidade do trabalho $x$ grau de interação e personalização (Adaptado de SCHM ENNER, 1986, p.25-27)}

O grau de intensidade do trabalho diz respeito à proporção entre o custo do trabalho e o custo do capital. Assim, serviços que apresentam alta intensidade de trabalho (ou de mão-de-obra) envolvem, relativamente, pequena quantidade de maquinaria e equipamentos e considerável mão-de-obra, esforço e custo. Por sua vez, serviços classificados como de baixa intensidade de mão-de-obra são caracterizados por níveis relativamente baixos de custos de trabalho em comparação com os custos de maquinaria e equipamentos.

O grau de interação e personalização combina dois conceitos similares, porém distintos: o grau de interação do cliente com o serviço e o grau de personalização do serviço para o cliente. A medida formada pela junção desses dois conceitos tem alto valor quando um serviço apresenta, simultaneamente, alto nível de interação e alto nível de personalização para o cliente. De forma similar, quando ambas as medidas são baixas, a medida da junção tem um valor baixo. Onde há uma mistura de alta interação com baixa personalização (ou o contrário) a medida da junção situa-se num valor médio.

Um serviço com alto nível de interação é aquele onde o cliente pode intervir ativamente no processo, sempre para solicitar serviços adicionais de um tipo particular, ou requisitar que algum aspecto do serviço não seja implementado. Um serviço com alto grau de personalização buscará satisfazer as particularidades individuais do cliente e, talvez, toda uma gama de preferências. 
Os serviços que garantem acesso à documentação civil básica estão agrupados no primeiro quadrante, onde predomina o custo dos equipamentos envolvidos sobre o custo da mão-de-obra. A participação do cidadão no processo está restrita às fases inicial e final, em que o serviço é, respectivamente, solicitado e recebido, denotando um baixo grau de interação e personalização.

Os serviços especializados de acesso à Justiça e de ações sociais preventivas da violência foram colocados no quarto quadrante. Na prestação desses serviços, o custo da mão-de-obra é preponderante, e a interação do cidadão com o prestador do serviço é fundamental, para que se consiga atingir resultados satisfatórios.

No quadro 5, o eixo horizontal contempla o grau de interação e personalização e o eixo vertical, o grau de intensidade da mão-de-obra.

\section{Quadro 5}

Grau de intensidade de mão-de-obra x grau de interação e personalização

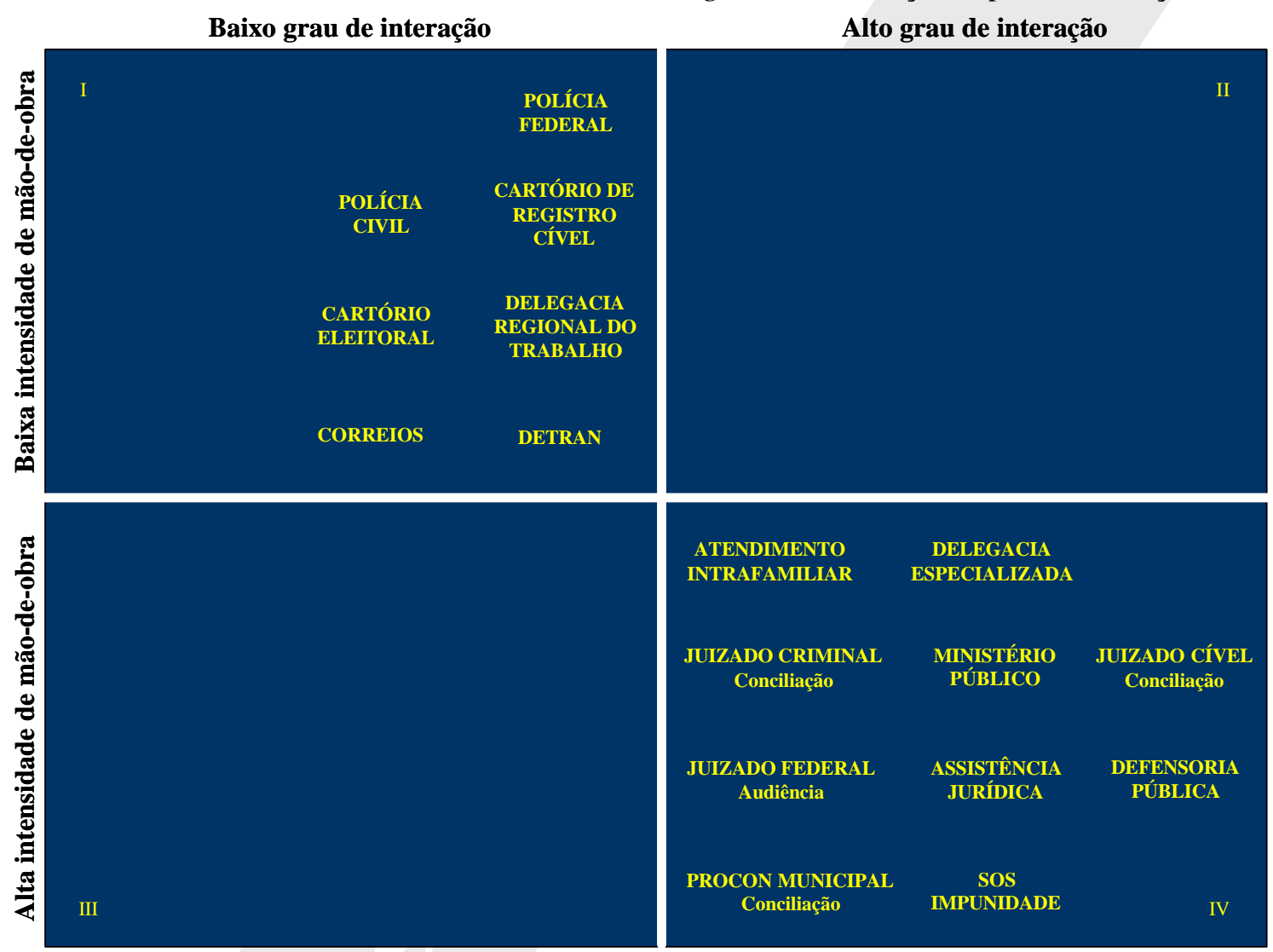

Fonte: elaborado pelos autores, com base nos levantamentos sobre os serviços.

A análise das variáveis abordadas permite identificar dois grupos de serviços com características opostas:

a)serviços vinculados ao acesso à documentação civil básica - em que o atendimento visa produzir um bem padronizado (documento) que será propriedade do cliente. Este determina o momento da demanda, mas não tem nenhuma influência direta no processo produtivo, participando no início (ao solicitar o serviço) e no final (ao recebê-lo). Sua avaliação da qualidade é determinada pelo atendimento recebido; o prazo de execução é rígido, envolvendo um ou, no máximo, dois contatos; e o prestador do serviço não tem autonomia para modificá-lo, pois seu trabalho segue procedimentos preestabelecidos. O custo do capital (investimentos realizados para que o serviço possa ser ofertado) predomina sobre o custo do trabalho (mão-de-obra envolvida na prestação do serviço);

b)serviços vinculados ao acesso à Justiça e às ações preventivas da violência - o atendimento é personalizado e dirigido à realidade ou "à mente" do cliente. Este não só determina o momento da demanda, como também 
define a natureza do serviço, interagindo com o prestador durante todo o processo produtivo. Sua avaliação da qualidade é determinada pelo atendimento recebido; a execução do serviço tem prazo flexível, sendo feita através de uma série de contatos que, de modo participativo e gradual, possibilitam que se chegue ao produto final. O prestador do serviço tem ampla autonomia para modificá-lo, seja valendo-se de abordagens diferenciadas, seja envolvendo outros profissionais ou redirecionando o fluxo de sua execução. $\mathrm{O}$ custo do trabalho predomina sobre o custo do capital.

A partir daqui, restringiremos nossa abordagem a este último grupo, por seu perfil mais sociotécnico, no sentido de que há realmente uma ação técnica numa realidade social a ser abordada, conforme Gadrey.

Esta ação está cercada por dois tipos de relações sociais: uma de "demanda de intervenção", que inicia uma relação de serviço, e outra de propriedade (a realidade a tratar é a da pessoa que demanda o serviço, ou se encontra sob seu controle). A natureza técnica do produto ou resultado (sua relação com a materialidade), pelo contrário, que era o fundamento das definições clássicas, não está presente nessa definição. O produto (do serviço) é a mudança de estado da realidade submetida à intervenção (2001, p. $31)$.

Além disso, esse grupo se identifica perfeitamente com a concepção de serviços de Gadrey, a qual pode ser visualizada na figura 1 .

\section{Figura 1}

Representação gráfica do "triângulo do serviço" de Gadrey

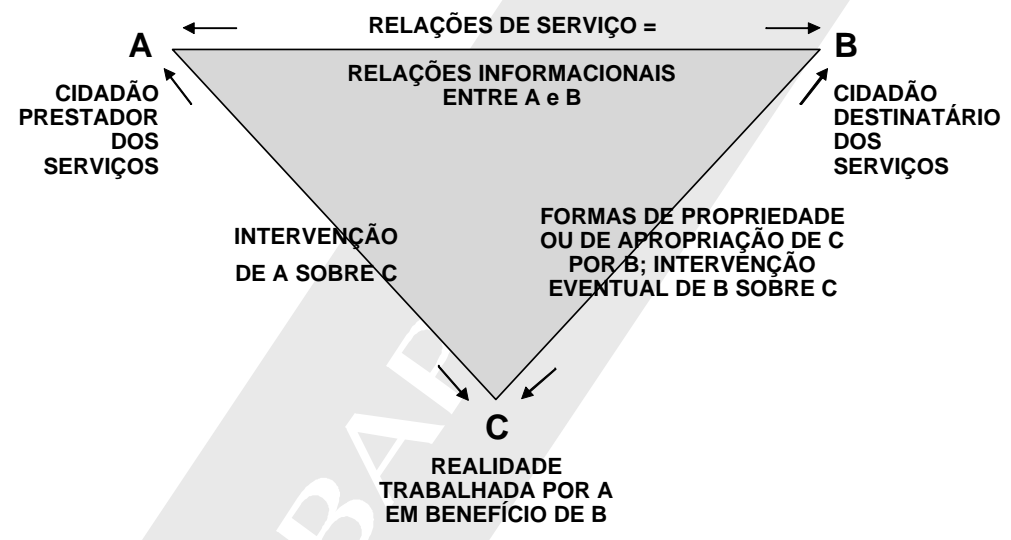

Fonte: J. Gadrey, L'économie des services, Col. Repères (Paris: La Découverte, 1992), p. 19.

Uma atividade de serviço é uma operação visando transformar uma realidade $C$, possuída ou utilizada por um consumidor $B$, realizada por um prestador de serviços $A$ por demanda de $B$, e freqüentemente em relação com ele, mas não resultando numa produção de um bem suscetível de circular economicamente, independentemente do suporte de $C$ (2001, p.32).

Outro motivo que nos leva a priorizar esse grupo de serviços é que ele se situa no âmbito daqueles que, do ponto de vista da sua participação em relação ao crescimento da oferta de empregos, têm progredido intensamente nos últimos anos. Nós o chamaremos, daqui em diante, de unidades de resolução de conflitos.

\section{As unidades de resolução de conflitos e os sistemas produtivos}

Uma vez determinadas as características das unidades de resolução de conflitos, após termos identificado os paradigmas sob os quais elas operam, iremos analisá-las sob o enfoque dos sistemas operacionais de Wild (1977, p.25-42). 
Segundo esse enfoque, existem sete estruturas básicas de arranjo dos sistemas produtivos, sendo que quatro delas referem-se à manufatura e suprimentos e as outras três aplicam-se a transportes e serviços. Apresentaremos o modelo dessas últimas, resumidamente, e nos deteremos um pouco mais na análise do modelo que mais guarda identidade com os serviços produzidos pelas unidades de resolução de conflitos. Esses modelos são representados pela seguinte simbologia: $\mathbf{O}$ para a função (manufatura, suprimento, transporte e serviço); $\boldsymbol{\nabla}$ para estoque físico ou inventário (em alguns casos, lista de espera); $\rightarrow$ para fluxo físico de entrada ou saída (materiais, máquinas e trabalho); e $\mathbf{C}$ para clientes do sistema.

Quando comparadas com as estruturas de manufatura e suprimento, diferenças estruturais importantes ficam evidentes no caso dos sistemas de transporte e serviços:

a) o cliente (beneficiário da função) também é o recurso físico de entrada; sem ele a função não se completa;

b) o cliente diz que tipo de benefício ele espera da função; e

c) enquanto na manufatura ou no suprimento o cliente age diretamente na saída, puxando os bens de consumo para fora do sistema, em transportes e serviços ele age diretamente na entrada, empurrando o sistema.

Portanto, são necessárias três estruturas diferentes para representar os sistemas de transporte e serviços:

a) descrevendo uma função de estoque, diretamente da situação do cliente; ou seja, os recursos de entrada são estocados, exceto os clientes, em relação aos quais não há tempo de espera;

\begin{tabular}{|c|c|c|}
\hline Estrutura básica & Descrição & Mneumônico* \\
\hline $\mathrm{C} \longrightarrow \mathrm{O} \longrightarrow$ & $\begin{array}{l}\text { Função executada a partir de recursos } \\
\text { em estoque e da chegada do cliente }\end{array}$ & $\mathrm{SCO}$ \\
\hline
\end{tabular}

* Fornece um meio simples para a descrição desses sistemas operacionais

b) descrevendo a situação-função para a fonte, com cliente em espera; ou seja, nenhum recurso de entrada é estocado. Contudo, entradas de clientes se acumulam numa lista de espera;

\begin{tabular}{ccc}
\hline Estrutura básica & \multicolumn{1}{c}{ Descrição } & Mneumônico* \\
\hline $\mathbf{C} \rightarrow \boldsymbol{O} \longrightarrow$ & $\begin{array}{l}\text { Função executada a partir dos recursos } \\
\text { em estoque no fornecedor, adquiridos } \\
\text { após a solicitação do serviço, e com o } \\
\text { cliente em espera. }\end{array}$ & DQO \\
\hline
\end{tabular}

* Fornece um meio simples para a descrição desses sistemas operacionais

c) descrevendo a situação-função do estoque, com cliente em espera, ou seja, todos os recursos de entrada são estocados e permitidos ficar em espera.

\begin{tabular}{|c|c|c|}
\hline Estrutura básica & Descrição & Mneumônico* \\
\hline $\mathrm{C}-$ & $\begin{array}{l}\text { Função executada a partir dos recursos } \\
\text { em estoque e com o cliente em espera. }\end{array}$ & SQO \\
\hline
\end{tabular}

* Fornece um meio simples para a descrição desses sistemas operacionais

As características distintivas dessas estruturas são a existência e a localização dos estoques e a presença do cliente em espera ou não. 
Confrontando as características das unidades de resolução de conflitos já levantadas com as estruturas básicas detalhadas anteriormente, identificamos a do tipo SCO como a que mais atende à operacionalização e à consecução dos objetivos propostos:

Nos sistemas com estrutura SCO, não há como ocorrer atendimento sem que haja demanda, isto é, não existe a possibilidade de formação de um estoque de atendimentos do qual o cliente retire a solução para o seu problema.

Nas unidades de resolução de conflitos, os recursos necessários ao atendimento (profissionais especializados, equipamentos, sistemas, ambiente etc.) ficam estocados, à espera da demanda do cliente.

Nos sistemas com estrutura SCO, o cliente empurra o sistema, pois é um recurso de entrada - é o beneficiário do atendimento -, e/ou provê um recurso físico de entrada, sem o qual não há atendimento.

Nas unidades de resolução de conflitos, o cliente não só determina o momento da demanda, como também define a natureza do serviço e interage com o prestador durante todo o processo produtivo, tendo voz ativa na elaboração do produto final.

Nos sistemas com estrutura SCO, a intenção é assegurar que os recursos necessários estejam disponíveis para o atendimento.

Nas unidades de resolução de conflitos, o cliente é atendido tão logo se apresente solicitando o serviço, em razão das situações de fragilidade e de dependência em que se encontra, na maioria das vezes.

Nos sistemas com estrutura SCO, espera-se que, em determinadas situações, todos os recursos disponíveis estejam comprometidos e, conseqüentemente, novos clientes que cheguem tenham de esperar. Como cliente em espera é algo que uma estrutura SCO não pode tolerar e como a previsibilidade do fluxo de clientes é possível apenas em certo grau, um mecanismo de tratamento dessas situações tem que ser previsto.

Nas unidades de resolução de conflitos, o atendimento é marcado em agenda e por senha, com a indicação da hora prevista para o contato com o prestador do serviço. O objetivo é que o ritmo de chegada dos clientes seja equivalente ao ritmo de atendimento.

Nos sistemas com estrutura SCO, o balanceamento dos recursos em estoque é outra necessidade, pois capacidade em excesso vai gerar, inevitavelmente, uma baixa produtividade de recursos, enquanto capacidade inadequada pode significar um péssimo atendimento ao cliente.

Nas unidades de resolução de conflitos, os sistemas de apoio ao processo de marcação de atendimento geram um conjunto de informações voltadas para a gestão dos recursos disponíveis, de maneira que as unidades se socorram mutuamente, alcançando o equilíbrio desejado.

\section{A escola sociotécnica e os serviços de resolução pacífica de conflitos}

Os pressupostos da escola sociotécnica apresentados adiante, e que servem para analisar as unidades de resolução de conflitos por outro prisma, foram extraídos e adaptados de Biazzi Júnior (1994, p.32).

A organização na perspectiva sociotécnica é, antes de qualquer coisa, um sistema aberto. Ela interage com o ambiente, é capaz de auto-regulação e possui a propriedade de eqüifinalidade; isto é, pode alcançar um mesmo objetivo a partir de diferentes caminhos e usando diferentes recursos.

Pela mobilidade que tem o prestador do serviço, as unidades de resolução de conflitos alcançam seus objetivos por diferentes caminhos, tornando cada abordagem e cada produto gerado altamente diferenciados.

Ela [a unidade de resolução de conflitos]é formada por dois subsistemas: o subsistema técnico - que são as máquinas, equipamentos, técnicos etc. - e o subsistema social - que são os indivíduos e grupos de indivíduos, seus comportamentos, capacidades, cultura, sentimentos e tudo de humano que os acompanha. Então, o 
subsistema social, assim enfocado pela escola sociotécnica, e o subsistema técnico de determinado sistema de trabalho devem ser considerados particularmente e em suas relações, e otimizados conjuntamente, para que os objetivos organizacionais sejam atingidos, ao mesmo tempo em que alcançamos o desenvolvimento e a integração dos indivíduos. Isso quer dizer que é preciso projetar em conjunto o sistema social e a tecnologia particular ao caso.

As unidades de resolução de conflitos apresentam esses dois subsistemas, o social e o técnico. Este atua como suporte operacional do primeiro, visto que é no domínio do subsistema social que ocorrem as ações-fim desses serviços, o trato das subjetividades dos atores sociais envolvidos e a interação desses mesmos atores, elementos fundamentais para que sejam atingidos resultados satisfatórios antiviolência.

A escola sociotécnica considera que o comportamento das pessoas diante do trabalho depende da forma de organização desse trabalho e do conteúdo das tarefas a serem executadas, pois o desempenho das tarefas e os sentimentos a elas relacionados - responsabilidade, realização, reconhecimento etc. - são fundamentais para que o indivíduo sinta orgulho e satisfação pelo seu trabalho.

As unidades de resolução de conflitos apresentam, ainda, a característica da visão cidadã sobre todos os atores sociais envolvidos; isto é, um olhar atento e integral para as necessidades dos cidadãos cuja realidade acarreta demanda por ajuda, dos profissionais especializados (também cidadãos) que disponibilizarão seus conhecimentos técnicos para transformar essa realidade e de terceiros (igualmente cidadãos) envolvidos por essa realidade.

\section{Unidades de resolução de conflitos à luz dos grupos semi- autônomos}

Ainda segundo Biazzi Júnior (1994, p.33), o foco principal dos estudos sociotécnicos recai sobre a organização dos sistemas produtivos, no âmbito dos indivíduos e suas atividades. Como opção ao arranjo tradicional das linhas de produção, esses estudos propõem a implementação de grupos semi-autônomos que devem ser entendidos como arranjos organizacionais produtivos que se caracterizam...

pela responsabilidade coletiva diante de um conjunto de tarefas, onde o arranjo do trabalho é definido pela participação de seus próprios membros, permitindo o aprendizado de todas as tarefas, a rotatividade nas funções, e facilitando uma interação cooperativa. O grupo semi-autônomo deve ainda ser responsável pelos recursos à sua disposição e ter autoridade para utilizá-los.

A análise das unidades de resolução de conflitos, à luz dos princípios mais significativos incidentes sobre os grupos semi-autônomos, complementa a percepção de que tais unidades se identificam com esses grupos e nos fazem avançar um pouco mais na composição das suas características.

Os princípios citados a seguir foram extraídos e adaptados de CHERNS (1976) p.783-792).

\section{Princípio da compatibilidade}

O processo de planejamento deve ser compatível com seus objetivos... O ponto que deve ser enfatizado é o de que um sistema social participativo não pode ser criado por decreto. (...) [O] planejamento de um sistema novo deve ser desenvolvido antes que a maioria das pessoas seja contratada. Até certo ponto, o trabalho delas deverá ser planejado com antecedência, mas esse ponto pode ser mantido num nível mínimo.

Nas unidades de resolução de conflitos, o âmbito mínimo de abordagem envolve a definição dos objetivos a serem alcançados, a construção da infra-estrutura necessária - características ambientais, sistemas, equipamentos etc. -, o dimensionamento da oferta de serviços e a definição das habilidades e do número de profissionais requeridos, sem o que a elaboração do desenho organizacional não se completa. A análise dos demais elementos ocorre no dia-a-dia, envolvendo os profissionais contratados no planejamento do trabalho que eles mesmos desenvolvem. 


\section{Princípio da mínima especificação crítica}

Esse princípio pode ser interpretado de dois modos: negativo e positivo. $\mathrm{O}$ negativo estabelece que não se especifique nada mais do que o absolutamente necessário; o positivo requer que se identifique aquilo que é necessário. Muito embora sempre haja necessidade de uma precisa definição sobre o que deve ser feito, raramente é necessário exatidão acerca de como deve ser feito.

Nas unidades de resolução de conflitos, busca-se verificar se há clareza na especificação do "que fazer", de modo que não haja dúvida entre os profissionais envolvidos quanto aos objetivos das unidades. Por outro lado, a autonomia das unidades abrange o "como fazer": os métodos de trabalho, a escolha do líder, a distribuição de tarefas entre os participantes da unidade, a definição das metas etc.

\section{Princípio do fluxo de informações}

Esse princípio estabelece que os sistemas de informação devem ser planejados para, em primeiro lugar, prover informação para o ponto onde ela é necessária para gerar uma ação. Projetados de maneira adequada, os sistemas de informação podem fornecer às equipes de trabalho, informações que as ajudem a controlar as variâncias que ocorrem em suas áreas e antecipar os eventos que causarão impacto em seu desempenho.

Nas unidades de resolução de conflitos, o objetivo é projetar um conjunto de sistemas capazes de prover as informações necessárias para o atendimento ao cidadão, conforme a realidade por ele apresentada, registrando o continuum dos atendimentos a ele vinculados - formando o seu prontuário e facilitando o envolvimento de outros profissionais especializados - e permitindo a busca e recuperação de procedimentos adotados anteriormente na abordagem de realidades similares.

\section{Princípio do critério sociotécnico}

Estabelece que as "variâncias", caso não possam ser eliminadas, devem ser controladas o mais próximo possível de seus pontos de origem. [...] Uma variância pode ser uma falha no atendimento, pode ser um erro ocorrido numa hora crítica quando foi necessária tomar uma decisão, uma falha de equipamento e assim por diante.

Nas unidades de resolução de conflitos, busca-se a construção de um modo de proceder, operar e conviver que privilegie as capacidades intelectuais e criativas dos profissionais alocados, que permita um aprendizado contínuo, gere suporte social e reconhecimento, que estabeleça uma clara relação entre os valores organizacionais e pessoais, que visualize todo o processo e o produto final e, que permita realimentar os resultados, levando à cooperação, à colaboração e ao comprometimento.

\section{Considerações finais - importância da adoção da perspectiva sociotécnica pelas unidades de resolução de conflitos}

No decorrer deste artigo, temos procurado demonstrar o funcionamento e as características das unidades de resolução de conflitos e como elas se identificam com os fundamentos, os princípios e as características da abordagem sociotécnica. Acreditamos que estruturá-las como grupos semi-autônomos soluciona a maioria dos conflitos de gestão do trabalho nessas unidades.

Podemos, ainda, tentar visualizar a conveniência da adoção desse enfoque, segundo duas óticas distintas: a da organizacional e a humana.

Do ponto de vista organizacional, a análise da abordagem sociotécnica mostra que ela favorece a adoção dos paradigmas desejáveis - qualidade, resolubilidade e interação, sem inobservância do paradigma vigente -, pela flexibilidade com que permite a atuação das unidades de resolução de conflitos. Assim, à medida que atendem 
ao cidadão, elas podem buscar atender aos novos paradigmas, uma vez que não existem normas e procedimentos prefixados e, conseqüentemente, paradigmas antigos sendo infringidos.

Do ponto de vista do ser humano, a análise da abordagem sociotécnica é tão ou mais importante quanto a do ponto de vista organizacional. A adoção da perspectiva sociotécnica tende a provocar um maior desenvolvimento e integração (psicológica e social) dos indivíduos. Ao mesmo tempo em que privilegia uma qualificação não fundamentada no saber formal ou na automação, essa perspectiva leva à participação e a uma autonomia responsável, baseada em conhecimentos técnicos e no relacionamento humano.

Além disso, sua adoção se apresenta como uma estratégia das mais eficazes para a sobrevivência e o desenvolvimento de equipamentos públicos cuja atuação esteja voltada para o turbulento mundo da violência, como é o caso dos centros integrados de cidadania.

Cabe ressaltar que, o fato de estudar a implantação de um determinado Centro Integrado de Cidadania não nos permite inferir que o resultado dessa análise possa ser estendido aos demais equipamentos urbanos dessa natureza. As questões aqui abordadas não devem ser generalizadas, mas apontam, tão somente, para um caminho que poderá ser utilizado por outros pesquisadores interessados no estudo da implantação/operacionalização desses centros de cidadania ou organizações com concepções semelhantes.

\section{Referências bibliográficas}

ANGELIM , G. P. 0 modelo de gestão de atendimento integrado: desafios e perspectivas. Brasília, DF: [s.n.], 2003. Mimeografado.

BIAZZI J R, F. 0 trabalho e as organizações na perspectiva sociotécnica. Revista de Administração de Empresas, v.1, n.34, p.30-37, jan./fev. 1994.

BRASIL. Presidência da República, Secretaria de Comunicação Social; Ministério da Justiça. Programa Nacional de Direitos Humanos. Brasília, DF, 1996.

Presidência da República. Plano Nacional de Segurança Pública. Brasília, DF: Presidência da República, 2000. (Coleção documentos da Presidência da República).

Presidência da República, Secretaria de Comunicação Social; Ministério da Justiça. Programa Nacional de Direitos Humanos PNDH' 2. Brasilia, DF, 2002a.

Presidência da República, Secretaria de Comunicação Social; Ministério da Justiça. Programa Nacional de Direitos Humanos PNDH' 2: plano de ação 2002. Braślia, DF, 2002b.

Ministério do Planejamento, Orçamento e Gestão. Programa de Qualidade no Serviço Público: transformando o setor público em benefício do cidadão. Brasília, DF, 2002c. p. 96-122. [Repertório 2002].

CHASE, R. B. Where does the customer fit in a service operation? Harvard Business Review, v.56, p.137- 142, Nov./Dec. 1978.

CHERNS, A. B. Principles of sociothechnical design. Human Relations, v.29, n.8, p.783- 792, 1976.

GADREY, J. Emprego, produtividade e avaliação do desempenho dos serviços. In: SALERNO, M. S. (Org.). Relação de serviço: produção e avaliação. São Paulo: Editora SENAC, 2001. (Série trabalho e sociedade).

LOVELOCK, C. H. Classifying services to gain strategic marketing insights. Journal of Marketing, v.47, p.9-20, Summer 1983.

SCHM ENNER, R. W. How can service businesses survive and prosper? Sloan Management Review, p.21- 32, Spring 1986.

WILD, R. Concepts for operations management. Chichester: John Wiley \& Sons, 1977. 